\title{
Synthesis, characterization and electrical study of nanocomposite of Polypyrrole with photoadduct of potassium hexacyanoferrate(III) and diethylenetriamine
}

\author{
Syed Kazim Moosvi*, Kowsar Majid and Tabassum Ara \\ Department of Chemistry, National Institute of Technology, Srinagar (J\&K) 190 006, India \\ *Email: msyedkazim@gmail.com
}

Nanocomposites have attracted intensive research, owing to their potential to combine desirable properties of different constituent phases. In this direction we have synthesized nanocomposite of polypyrrole (PPY) with photoadduct of $\mathrm{K}_{3} \mathrm{Fe}(\mathrm{CN})_{6}$ and diethylenetriamine via in-situ oxidative chemical polymerisation. Photoadduct was synthesised by photoirradiation followed by substitution with diethylenetriamine ligand using Osram photo lamp. The successful synthesis of photoadduct was supported by Elemental analyzer, UV-Vis and FTIR. From elemental analysis, the empirical formula assigned to the synthesized photoadduct was $\left[\mathrm{Fe}(\mathrm{CN})_{3}(\right.$ dien $\left.)\right] \mathrm{H}_{2} \mathrm{O}$. Photoadduct obtained was then milled in high energy ball mill to reduce it to nano size, which is confirmed from X-ray diffraction. Nanocomposite of photoadduct with PPY was then prepared by oxidative chemical polymerization using $\mathrm{FeCl}_{3}$ as oxidant. FTIR spectra of nanocomposite revealed the successful synthesis of nanocomposite. SEM analysis revealed distinct morphological features of photoadduct, PPY and nanocomposite. XRD showed monoclinic structure of photoadduct, which is retained in nanocomposite. The nanocomposite was found to show high value of dielectric constant and AC-conductivity. The dielectric constant decreases rapidly with increase in frequency in low frequency region while it shows almost frequency independent behaviour at high frequency region as shown in Figure 1.

The AC-conductivity has been found to increase with increase in frequency (Figure 2). This can be attributed to the interfacial polarization owing to heterogeneous nature of nanocomposite, as the two phases of nanocomposite differ from each other in dielectric constant and conductivity [1].

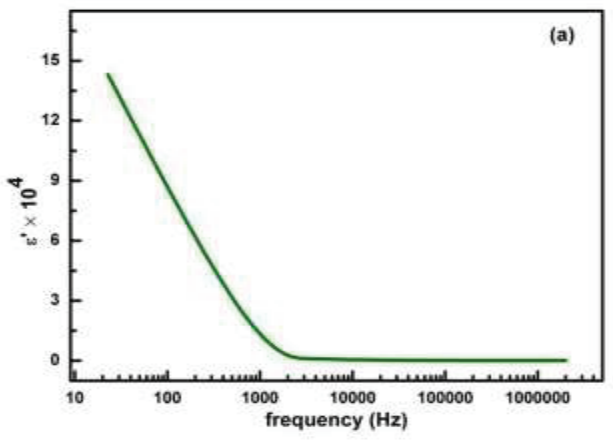

Figure 1: Variation of dielectric constant with frequency

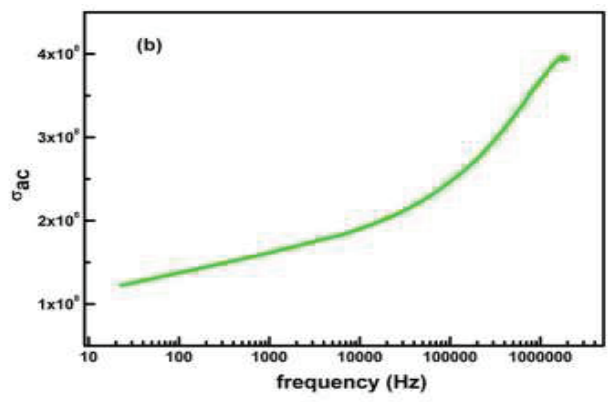

Figure 2: Variation of AC-conductivity with frequency

\section{Reference}

1. D. C. Tiwari, V. Sen, R. Sharma, Indian J. Pure Appl. Phys. 50, 49 (2012). 